\title{
Appendicular pseudodiverticula and acute appendicitis. Our 12-year experience
}

\author{
María del Carmen Manzanares-Campillo, Ricardo Pardo-García and Jesús Martín-Fernández \\ Department of General and Digestive Surgery. Hospital General de Ciudad Real. Ciudad Real, Spain
}

\begin{abstract}
Introduction: the presence of diverticula and their complications in the cecal appendix is an uncommon disease. We present a series of 13 patients with this condition, and perform a review of the literature.

Patients and method: we carried out a retrospective study of patients undergoing appendectomy for acute appendicitis in the last twelve years in our department. The pathological examination of these episodes revealed 13 cases with a diagnosis of diverticular disease, all of them consisting of pseudodiverticula. Their clinical manifestations, laboratory results, imaging tests, and histology were analyzed, and findings were compared to those in the previous literature.

Results: the incidence of diverticular disease in our setting was 13 cases $(0.8 \%)$ among 1,634 appendectomies for acute appendicitis. Diverticulitis was found in 8 patients (61.5\%), and diverticulosis (38.5\%) in 5. Appendicular perforation was more common in patients with diverticular disease $(53.8 \%)$ as compared to those without this condition (31.1\%).

Conclusions: complicated diverticular disease in the vermiform appendix of adult patients may result in insidious, recurrent manifestations that may confound preoperative diagnosis. A higher risk for appendicular perforation renders appendectomy the therapy of choice, even prophylactically when the condition is incidentally identified preoperatively.
\end{abstract}

Key words: Appendicular diverticulosis. Appendicular diverticulitis. Acute appendicitis.

Manzanares-Campillo MC, Pardo-García R, Martín-Fernández J. Appendicular pseudodiverticula and acute appendicitis. Our 12year experience. Rev Esp Enferm Dig 2011; 103: 582-585.

Received: 17-11-10

Accepted: 04-03-11.

Correspondence: María del Carmen Manzanares Campillo. Department of General Surgery and Digestive Diseases. Hospital General de Ciudad Real. C/ Obispo Torija, s/n. 13004 Ciudad Real. Spain.

e-mail: carmenmc2010@gmail.com

\section{INTRODUCTION}

The finding of diverticula in the cecal appendix represents an uncommon condition (0.004-2.1\%) that was first described in 1893 by Kelynack (1-3). Diverticula are more common in the colon, with a decreasing incidence from sigma $(90 \%)$, to descending colon $(45 \%)$, to transverse colon (15\%), to ascending colon (10\%), to cecum $(5 \%)$, to rectum $(0.5 \%)(4,5)$.

The classification of diverticula into true and false (or pseudodiverticula) types is based on histological criteria pointing to their congenital or acquired origin, respectively.

A diagnosis is rarely reached preoperatively in the absence of a high index of suspicion and corroborative imaging tests (ultrasounds, computerized axial tomography). Therefore, these patients are usually diagnosed with and treated for acute appendicitis. However, despite similarities, both conditions have subtle differentiating characteristics. A definitive diagnosis is established following a pathological examination of surgical specimens, with four morphological types according to the classification by Lipton et al. $(5,6)$.

The singularity of this condition, present in the literature as isolated case reports, led us to present 13 cases of pseudodiverticula emerged from twelve years of practice in our department, to compare their clinical, laboratory, and pathological characteristics with findings in the previous literature, and to provide a review of this disease.

\section{PATIENTS AND METHODS}

We performed a restrospective study of appendectomies for acute appendicitis in our department. From January 1, 1998 to June 30, 2010, 1634 patients were operated upon for acute appendicitis, 13 of whom had appendicular pseudodiverticula. 
A review of medical records provides the following data: age, sex, clinical manifestations, diagnostic tests (lab and imaging tests), surgical technique, and pathological examination.

The statistical study was performed using the SPSS for Windows software, version 14.0. Quantitative variables were reported as mean (median for non-Gaussian variables) and range, whereas discrete variables were reported as number of cases and percentage. A comparison of discrete variables was performed using the chi-squared method, and Student's t-test was used for mean differences. p-values < 0.05 were considered statistically significant.

\section{RESULTS}

The sample of 13 patients included in the study was selected based on a histological diagnosis of appendicular diverticular disease for 12 cases, and intraoperatively for 1 case (Fig. 1), from a total of 1,634 individuals undergoing appendectomy for acute appendicitis in the last twelve years in our department.

The incidence of cases with appendicular diverticula was $13(0.8 \%)$. Regarding sex, they were more prevalent in males $-9(69.2 \%)$ - than in females $-4(30.8 \%)$ - and mean age was 49.8 years (range 19-87 years). Appendicitis has an overall distribution that is similar for both sexes -males, $987(60.9 \%)$ and females, $634(39.1 \%)$, with a significantly younger mean age of 25.6 (range 3-99).

Morphological types as suggested by Lipton et al. (5) allow a classification of appendicular diverticula in our study as follows (Table I):

- Type II: acute appendicitis and acute diverticulitis. We found a frequency of 8 cases $(61.54 \%), 6(75 \%)$ of which were perforated.

- Type III: acute appendicitis and non-complicated appendicular diverticula. Frequency was $5(38.5 \%)$ cases, 1 (20\%) of which was perforated.

Overall, the frequency of perforation among patients with diverticular disease and acute appendicitis was 7 $(53.8 \%)$, almost twice as high as in patients with appendicular inflammation alone [505 (31.1\%)], with results reaching statistical significance.

\section{DISCUSSION}

Appendicular pseudodiverticula, even considering the rarity of diverticular disease in the appendix (mean incidence of $1 \%$ ), are the most common presentation form. Their incidence is estimated as $0.77 \%$ in appendectomy specimens, and $0.66 \%$ in necropsy specimens, versus true diverticula, which only develop in $0.014 \%$ of surgical specimens and represent 1 to $6.6 \%$ of appendicular diverticulosis $(5-7,8)$.

False diverticula, pseudodiverticula or acquired diverticula seem to result from increased pressure on low-resis-

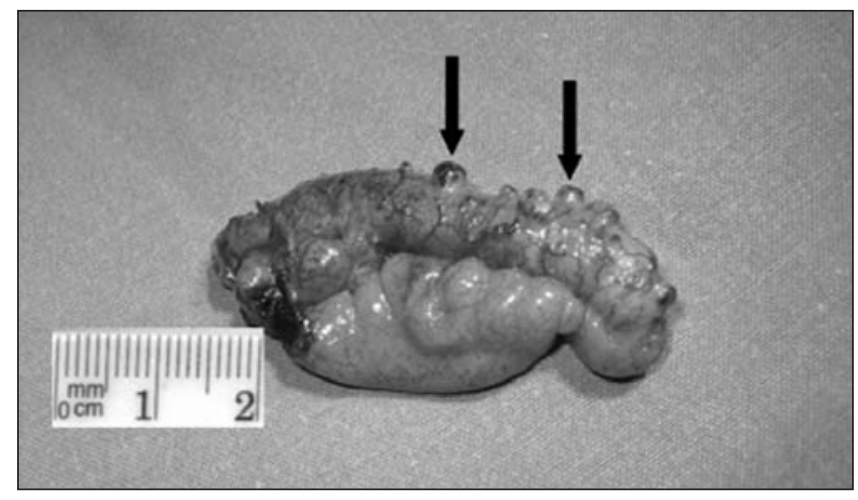

Fig. 1. Cecal appendix with pseudodiverticula (black arrows).

tance spots in the appendicular wall, including vascular hiatuses and inflamed areas, from a combination of luminal obstruction -appendicular diverticula have been reported as concomitant with carcinoids, cystadenomas and mucoceles- and active muscle contraction. Therefore, these diverticula result from pulsion and include only mucosa $(1,5,7)$.

In our case series we only report pseudodiverticula, with an incidence of $13(0.8 \%)$, which is similar to that in the literature.

True or congenital diverticula (fewer than 50 cases in the whole literature) result -according to the most widely accepted theory- from abnormal bowel repermeabilization during the intestine's solid phase. They have been on occa-

Table I. Clinical and epidemiological characteristics of appendicular diverticula

\begin{tabular}{llll}
\hline Types according & Age (years) & Imaging technique & Perforation \\
to Lipton et al. & Gender & &
\end{tabular}

Type II

(Appendicitis +

diverticulitis)

$\begin{array}{lll}\text { 60/F* } & \text { Ultrasounds } & \text { Yes } \\ 52 / \mathrm{M}^{* *} & \text { Ultrasounds } & \text { Yes } \\ \text { 41/F } & \text { Ultrasounds } & \text { Yes } \\ 55 / \mathrm{M} & \text { No } & \text { Yes } \\ \text { 27/M } & \text { No } & \text { Yes } \\ 52 / \mathrm{M} & \text { No } & \text { Yes } \\ \text { 31/F } & \text { Ultrasounds } & \text { No } \\ 59 / \mathrm{M} & \text { No } & \text { No }\end{array}$

Type III

(Appendicitis +

diverticulosis)

$\begin{array}{lll}\text { 62/M } & \text { CT*** } & \text { No } \\ 58 / \mathrm{M} & \text { No } & \text { No } \\ \text { 19/M } & \text { No } & \text { No } \\ 87 / \mathrm{F} & \text { No } & \text { Yes } \\ 45 / \mathrm{M} & \text { No } & \text { No }\end{array}$

${ }^{\star}$ F: female. ${ }^{* *} \mathrm{M}$ : male; ${ }^{* * *} \mathrm{CT}$ : computerized tomography. 
sion associated with trisomy D 13-15 or pancreatic cystic fibrosis $(1,5,7,9)$.

Diverticula may be single or multiple, most commonly occur within the distal third of the appendix (60\%), on its mesenteric side $(60 \%)$, and their size is usually smaller than $0.5 \mathrm{~cm}(5,10,11)$.

Lipton et al. classified appendicular diverticulosis into four morphological types $(5,6,9-12)$ :

- Type 1: acute diverticulitis in a non-inflamed appendix.

- Type 2: diverticulitis and acute appendicitis.

- Type 3: non-complicated diverticulum and acute appendicitis.

- Type 4: non-complicated diverticulum and normal appendix.

They also added various subtypes according to the presence or absence of appendicular perforation.

Appendicular diverticulosis is usually asymptomatic. Most common complications such as perforation and inflammation cause abdominal pain that mimics acute appendicitis. Insidious, intermittent, prolonged pain usually in the absence of nausea, vomiting or anorexia, and more common in males in their forties, are characteristics considered to be differential from acute appendicitis by some authors $(1,5-7,8,13)$.

In our department, as in the literature, the condition was more prevalent in males $(9,69.2 \%)$ with a mean age of 49.8 years at presentation. In all cases patients sought help for abdominal pain lasting from 12 hours to 10 days. Data such as presence of low fever and mild leukocytosis were common, not so gastrointestinal symptoms such as nausea and vomiting.

Appendicular perforation in the presence of diverticulitis is four times as common as in its absence $(66 \%$ of cases), with patient mortality increasing by $30 \%$ as compared to simple acute appendicitis $(1,2,6,7,9-15)$. In our case, in the presence of appendicular diverticulitis the percentage of perforations was approximately twice as high as in its absence, with one case of perforation with diverticulosis -a finding less common in the literature $(<10 \%$ of cases) (10).

Other complications of appendicular diverticulosis, including diverticular mouth edema, acute bleeding from appendicular artery rupture, appendicular pseudomyxoma, and periappendicular fibrosis are reported less frequently (7).

The diagnosis is usually incidental following the pathological study of the surgical specimen, and proportional to the pathologist's efforts in its search. They have also been described as incidental radiographic findings (barium enema, ultrasounds, computerized tomography) and as findings during laparotomy $(1,3,5,7,8,10-12,14,16-21)$. In our series preoperative imaging techniques did not contribute to definitive diagnoses. A diagnosis was mostly arrived at by histology, except for an intraoperative case.

The management of complicated diverticular disease does not differ from that for acute appendicitis, namely appendectomy. Prophylactic appendectomy is recommended for asymptomatic cases incidentally diagnosed either radiographically or during laparotomy $(1,4,5,7,9,10$, $12,14,22$ ) given the higher risk of appendicular perforation and mortality associated with this condition's complicated form.

\section{REFERENCES}

1. Place RJ, Simmang CL, Huber PJ Jr. Appendiceal diverticulitis. South Med 2000;93(1):76-9.

2. Greenberg R, Avital S, Kashtan H, Skornik Y. Diverticular disease of the appendix. Harefuah 1997;132(3):180-2.

3. Kubota T, Omori T, Yamamoto J, Nagai M, Tamaki S, Sasaki K. Sonographic findings of acute appendiceal diverticulitis. World J Gastroenterol 2006;12(25):4104-5.

4. Martínez-Falero J. Divertículos en el apéndice vermicular. Rev Esp Enferm Dig 1990;78(3):175-7.

5. Martínez R, Martínez AM, Escudero B, Pacheco R, Gil M, Cabello J. Diverticulosis verdadera apendicular asociada a apendicitis aguda. Cir Esp 2000;67:204-6.

6. Lipton S, Estrin J, Glasser I. Diverticular disease of the appendix. Surg Gynecol Obstet 1989;168(1):13-6.

7. Balsalobre M, Piñero A, Torregrosa N, Tamayo ME, Galindo PJ, Martínez-Barba E, et al. Diverticulosis apendicular: causa infrecuente de dolor en la fosa ilíaca derecha. Cir Esp 2002;72(5):297-9.

8. Bianchi A, Heredia A, Hidalgo LA, García-Cuyás F, Soler MT, Bas M, et al. Enfermedad diverticular del apéndice cecal. Cir Esp 2005; 77(2):96-8.

9. Friedlich M, Malik N, Lecompte M, Ayroud Y. Diverticulitis of the appendix. Can J Surg 2004;47(2):146-7.

10. Majeski J. Diverticulum of the vermiform appendix is associated with chronic abdominal pain. Am J Surg 2003;186:129-31.

11. Karibi H, Clarke LE, Tzanas CD. Appendiceal diverticulitis. Amer Surg 2006;72(3):221-3.

12. Barc RM, Rousset J, Maignien B, Lu M, Prime-Guitton CH, García JF. Diverticula of the appendix and their complications: value of sonography (review of 21 cases). J Radiol 2005;86:299-309.

13. Niwa H, Hiramatsu T. A rare presentation of appendiceal diverticulitis associated with pelvic pseudocyst. World J Gastroenterol 2008;14(8): 1293-5.

14. Rivero L, Cardoza F. Apendicitis aguda y divertículos del apéndice cecal. Informe de un paciente. Cir Gen 2000;22:351-3.

15. Wetzig NR. Diverticulosis of the vermifrom appendix. Med J Aust 1986;145(9):464-5.

16. Yamauchi M, Miyamoto M, Takeuchi K, Fukuhara T. Sonographic appearance of appendiceal diverticulitis. Inter Med 2008;47: 11534.

17. Iki K, Echigo M, Nogami A, Iwamoto S, Takeo T, Tsumoda T, et al. Preoperative diagnosis of acute appendiceal diverticulitis by ultrasonography. Surgery 2001;130:87-9.

18. Lee KH, Lee HS, Park SH, Bajpai V, Choi YS, Kang SB, et al. Appendiceal diverticulitis: diagnosis and differentiation from usual acute appendicitis using computed tomography. J Comput Assist Tomogr 2007;31(5):763-9.

19. Wetzig NR. Diverticulosis of the vermiform appendix. Med J Aust 1986;145(9):464-5.

20. Navarro JA, Tárraga PJ, Rodríguez JA, López MA. Validity of tests performed to diagnose acute abdominal pain in patients admitted at an emergency department. Rev Esp Enferm Dig 2009;101:610-8.

21. García A, Martín G, Pérez MD, Bernardos L, Turégano F. Chronic right lower quadrant pain due to retained barium. Rev Esp Enferm Dig 2009;101(2):145-52.

22. Aranda-Narváez JM, González-Sánchez AJ, Marín-Camero N, Montiel-Casado C, López-Ruiz P, Sánchez-Pérez B, et al. Conservative approach versus urgent appendectomy in surgical management of acute appendicitis with abscess or phlegmon. Rev Esp Enferm Dig 2010; 102(11):648-52. 